\title{
Espacio, poder y gubernamentalidad. Arquitectura y urbanismo en la obra de Foucault
}

\section{Space, Power and Governmentality. Architecture and Urban Planning in the Work of Foucault}

Artículo recibido el 7 de febrero de 20I7; devuelto para revisión el 2 de marzo de 20I7; aceptado el II de octubre de 20I7, http://dx.doi.org/IO.2220I/iie.I8703062e.20I8.II2.2634

Jorge León Casero Universidad de Zaragoza-Departamento de Filosofía, España. jleon@ unizar.es.

Publicaciones más relevantes En coautoría con Lourdes Diego Barrado y Jorge Fernández-Santos, eds., Open Sourcing. Investigación y formación avanzada en arquitectura (Zaragoza: Ediciones Universidad San Jorge, 2016); "La arquitectura de la seducción. Un análisis de las arquitecturas digitales en la sociedad de consumo", Arte, Individuo y Sociedad 27, núm. 3 (2015): 445-460; "La arché-tectura contra Deleuze", en Luis Arenas, ed., El efecto Deleuze (Zaragoza: Erial, 2016), I83-210.

Julia Urabayen Universidad de Navarra-Departamento de Filosofía, España. jurabayen@unav.es.

Publicaciones más relevantes En coedición con Jorge León Casero, "El humanismo es una violencia propia de bestias: filosofando a martillazos, a partir de Levinas y Derrida, la medida de lo humano y lo humano como medida", Anales del Seminario de Historia de la Filosofía, vol. 33 (2016): 253-284; con Sánchez Migallón, eds., Reflection on Morality in Contemporary Philosophy. Performing and Ongoing Phenomenology (Georg Olms Verlag, 20I4), 7; y ed. de Levinas confrontado (México: Porrúa, 20I4).

Líneas de investigación

Estética; arquitectura; urbanismo; corrientes actuales de filosofía; filosofía política contemporánea.

Lines of research Aesthetics; architecture; urbanism; current philosophical schools; contemporary political philosophy.

Resumen Según Foucault, mientras que en las sociedades disciplinares se "arquitecturizaba” modularmente el espacio físico de la ciudad como dispositivo panóptico de vigilancia y normalización de los individuos, las sociedades biopolíticas han desarrollado un doble dispositivo de 
gestión del riesgo. Por una parte, estadística y cartografía han construido tanto el nuevo objeto de gobierno (población) como el nuevo medio en el que actuar (territorio), entendiendo ambos como una matriz de datos geolocalizados. Por la otra, la función del arquitecto-urbanista ha dejado de ser la formalización panóptica del espacio para pasar a ser la adecuación socioterritorial del medio que promueva una autogestión productiva del espacio por parte de su propia población. La consecuencia del primer movimiento ha sido la proliferación de las smart cities. La del segundo, las políticas de regeneración urbana de la OCDE y la UE. El presente artículo analiza este cambio gubernamental de gestión urbana y muestra los dispositivos de poder que yacen bajo los discursos de legitimación de las smart cities y el urbanismo participativo.

Palabras clave Foucault; biopolítica; smart cities; urbanismo participativo; regeneración urbana.

Abstract According to Foucault, while in disciplinary societies the city's physical space was "made an architectural space" modulating it as a panoptic device to monitor and normalize individuals, biopolitical societies have developed a dual risk management device. On the one hand, statistics and cartography have built the new object of government (population) as well as the new medium in which to act (territory), together understood as a matrix of geo-localized data. On the other hand, the function of the architect-urban planner has ceased to be the panoptic formalization of space to become the socio-territorial adaptation of the medium that promotes productive self-management of space by its population. The consequence of the first movement has been the proliferation of smart cities. The second, the urban regeneration policies of the OECD and the EU. This article analyzes this governmental change of urban management, showing the power devices that underlie the legitimacy discourses of smart cities and participatory planning.

Keywords Foucault; biopolitics; smart cities; participatory planning; distressed urban areas. 


\author{
JORGE LEÓN CASERO \\ JULIA URABAYEN \\ UNIVERSIDAD DE ZARAGOZA-DEPARTAMENTO DE FILOSOFÍA \\ UNIVERSIDAD DE NAVARRA-DEPARTAMENTO DE FILOSOFÍA \\ ESPAÑA
}

\title{
Espacio, poder \\ y gubernamentalidad \\ Arquitectura y urbanismo en la obra de Foucault
}

Foucault y las disciplinas del espacio

\begin{abstract}
-gún Foucault, tanto la arquitectura y el urbanismo, por una parte, como la praxis social y las formas de gobierno, por otra, resultan incomprensibles si se les analiza por separado. Para el autor francés resulta "un poco arbitrario tratar de disociar la práctica efectiva de la libertad [de] la práctica de las relaciones sociales y las distribuciones espaciales. A partir del momento en que se separan esas cosas, se vuelven incomprensibles. Cada una sólo puede comprenderse a través de la otra". ${ }^{\mathrm{I}}$

Más allá de sus conocidos análisis panópticos sobre las prisiones, ${ }^{2}$ los cursos impartidos por Foucault en el Collège de France durante la década de 1970

I. Michel Foucault, El cuerpo utópico. Las heterotopías, trad. Víctor Goldstein (Buenos Aires: Ediciones Nueva Visión, 2009), 95.

2. Michel Foucault, Vigilar y castigar, trad. Aurelio Garzón del Camino (Madrid: Siglo XXI, 2005). Estudio no exento de polémica con Virilio por el uso de ciertos materiales de estudio: "uno de sus colaboradores era Jacques Donzelot. Y sucedió que Jacques Donzelot se sentó en el panel examinador de uno de mis estudiantes que estaba investigando las prisiones [...] La prueba de ello es que las ilustraciones ofrecidas por Foucault en su libro pueden ser directamente rastreadas hasta la tesis de mi alumno" ("One of his collaborators was Jacques Donzelot. And Jacques
\end{abstract}


permiten apreciar cómo el horizonte de sentido de sus estudios espaciales sigue una lógica dinámica que va desde el interés por la arquitectura o "arquitecturación" panóptica del espacio propia del poder disciplinar hasta una consideración estadística de la población y el territorio propia del poder biopolítico.

Una de las principales dificultades en el análisis del nuevo papel que el arquitecto-urbanista está adquiriendo con el desarrollo de las políticas europeas de regeneración urbana radica precisamente en que el estudio de la obra de Foucault referente al territorio y la población se ha realizado la mayor parte de las veces desde disciplinas como la geografía y la sociología a partir del denominado "giro espacial" de las ciencias sociales, ${ }^{3}$ mientras que el interés de la arquitectura y el urbanismo por la obra del pensador francés se ha mantenido durante décadas centrado casi exclusivamente en torno al análisis de los dispositivos panópticos y el concepto de heterotopía. ${ }^{4}$

Donzelot happened to sit on the examination board of one of my students who was doing research on prisions [...] The proof of that is that the illustrations provided in Foucault's book can be directly traced to my student's thesis"), en Paul Virilio, "From Modernism to Hypermodernism and Beyond", en John Armitage, ed., Virilio Live: Selected Interviews (Londres: SAGE, 200I), 34.

3. Edward Soja, Thirdspace: Journeys to Los Angeles and Other Real-and-Imagined Places (Oxford: Blackwell, 1996), Sophie Watson y Katherine Gibson, eds., Postmodern Cities and Spaces (Oxford: Blackwell, 1995), Jeremy Crampton y Stuart Elden, Space, Knowledge and Power. Foucault and Geography (Burlington: Ashgate, 2007).

4. Michiel Dehaene y Lieven de Cauter, eds., Heterotopia and the City (Londres y Nueva York: Routledge, 2008). La aplicación del término "heterotopía" en la disciplina arquitectónica ha sido de lo más profusa y variopinta. Por citar sólo algunos casos, dicho concepto se ha utilizado para referirse a la arquitectura islámica (Jo Tonna, "The Poetics of Arab-Islamic Architecture", Muqarnas, núm. 7 [1990]: I82-197), el museo del Pacific Island Culture (Miriam Kahn, "Heterotopic Dissonance in the Museum Representation of Pacific Island Cultures", American Anthropologist 97, núm. 2 [1995]: 324-338), las logias masónicas y las primeras fábricas (Kevin Hetherington, The Badlands of Modernity: Heterotopia and Social Ordering [Londres: Routledge, 1997]), la nueva biblioteca pública de Vancouver (Loretta Lees, "Ageographia, Heterotopia, and Vancouver's New Public Library”, Environment and Planning DI7, núm. I [1997]: 69-86), los colegios femeninos del siglo XIX (María Tamboukou, "Educational Heterotopias and the Self' Pedagogy", Culture \& Society I2, núm. 3 [2004]: 399-4I4), los templos budistas de Swayambhu en el valle Kathmandu (B. M. Owens, "Monumentality, Identity and the State: Local Practice, World Heritage, and Heterotopia at Swayambhu, Nepal”, Anthropological Quarterly 75, núm. 2 [2002]: 269-316), el centro Georges Pompidou y el museo Guggenheim de Bilbao (Grahame Shane, "Heterotopias of Illusion: from Beaubourg to Bilbao and Beyond", en Heterotopia and the City, 259-27I) o los establecimientos de comida rápida y las oficinas de teleoperadores (Costas M. Constantinou, "Heterotopias of Production. Unveiling the Everydayness of the Cypriot Economy", The Cyprus Review, núm. 26 [2014]: I27-I43). 
Además, en la mayoría de las ocasiones y salvo excepciones contadas, 5 la ambigüedad del concepto de heterotopía, que llevó al propio Foucault a abandonarlo en sus estudios espaciales posteriores, se ha resuelto completa e ideológicamente en su importación a la disciplina arquitectónica desde un punto de vista exclusivamente (neo)liberal. ${ }^{6}$ De este modo, la heterotopía ha sido vista como un lugar privilegiado donde la yuxtaposición espacial de diferencias es capaz de favorecer el empoderamiento de los ciudadanos frente a la homogeneización y normalización provocadas por el poder disciplinario, ${ }^{7}$ lo que reduce toda la complejidad de lo social a una mera relación de causa-efecto entre libre comercio y heterotopía. A este respecto, tanto centros comerciales ${ }^{8}$ como intercambiadores, ${ }^{9}$ slums y campamentos urbanos ${ }^{\mathrm{IO}}$ e incluso gated communities, ${ }^{\text {II }}$ se han amalgamado sin crítica alguna y defendido como paradigmas de la libertad de la sociedad civil frente al Estado.

5. Daniel Defert, "Foucault, Space and the Architects", en Politics/Poetics: Documenta X-The Book (Ostfildern-Ruit: Hatje Cantz Verlag, 1997), 274-283; Sven-Olov Wallenstein, Essays. Lectures (Estocolmo: Axl Books, 2007), 36I-404.

6. Contrariamente a lo propuesto por arquitectos y urbanistas, geógrafos como Edward Soja incidieron hace años en el carácter "frustrantemente incompleto, inconsistente, incoherente" (Marco Cenzatti, "Heterotopias of Difference", en Heterotopia and the City, 75) del concepto de heterotopía.

7. Heidi Sohn, "Heterotopia: Anamnesis of a Medical Term", en Heterotopia and the City, 4I-5O.

8. Rem Koolhaas, The Harvard Design School Guide to Shopping (Nueva York: Taschen, 2002); Kathleen Kern, "Heterotopia of the Theme Park Street", en Heterotopia and the City, I05-II6; Clement Orillard, "Between Shopping Malls and Agoras: a French History of 'Protected Public Space", en Heterotopia and the City, II7-I36; Douglas Muzzio y Jessica Muzzio-Rentas, "A Kind of Instinct: the Cinematic Mall as Heterotopia”, en Heterotopia and the City, I37-I5O.

9. Lee Stickells, "Flow Urbanism: the Heterotopia of Flows", en Heterotopia and the City, 247-258. Io. Maureen Heyns, "Rubbing the Magic Lamp: Heterotopian Strategies in London's Eastern City Fringe", en Heterotopia and the City, 227-246; Robert Cowherd, "The Heterotopian Divide in Jakarta: Constructing Discourse, Constructing Space", en Heterotopia and the City, 275-286; Michel Agier, "Le Campement urbain comme hétérotopie et comme refuge. Vers un paysage mondial des espaces précaires”, Brésil(s). Sciences Humaines et Sociales, núm. 3 (2OI3): II-28.

II. Derek Hook y Michele Vrdoljak, “Gated Communities, Heterotopia and a 'Rights' of Privilege: a 'Heterotopology' of the South African Security-park”, Geoforum, núm. 33 (2002): I95-219; Setha Low, "The Gated Community as Heterotopia”, en Heterotopia and the City, I53I64; Hugh Bartling, "A Master-planned Community as Heterotopia: The Villages, Florida”, en Heterotopia and the City, I65-I78; Xavier Guillot, "The 'Institutionalization' of Heterotopias in Singapore", en Heterotopia and the City, I79-I88; Alessandro Petti, "Dubai Offshore Urbanism", en Heterotopia and the City, 287-296. 
Frente a esta nueva apología arquitectónica de las "máquinas de libertad", conviene recordar el rechazo explícito de Foucault hacia las mismas: "Los hombres soñaron con máquinas liberadoras. Pero por definición no hay máquinas de libertad. Garantizar la libertad no es algo que corresponda a la estructura de las cosas. La libertad es una práctica. Nada es funcionalmente liberador". ${ }^{22}$

El presente artículo realiza un análisis del cambio de funcionamiento que han experimentado la arquitectura y el urbanismo como técnicas de control gubernamental con el paso del paradigma disciplinario al biopolítico. Ello nos permitirá evidenciar cómo los análisis centrados en torno a la arquitectura como técnica panóptica y la "liberación" de la misma mediante el diseño de heterotopías ha funcionado como una ideología que oculta el actual funcionamiento de la disciplina arquitectónica y urbanística. Para ello dividiremos el artículo en tres apartados. En el primero analizaremos el empleo disciplinar de la arquitectura como modulación panóptica del espacio físico que garantice la vigilancia y normalización de los individuos tal y como se realizaba en la ciudad barroca y neoclásica.

En el segundo mostraremos los dos principales cambios gubernamentales que posibilitaron la desaparición de la ciudad como máquina de normalización de los individuos, y la aparición de las actuales smart cities como máquinas de gestión de datos: la construcción de un nuevo objeto de gobierno (la población y no el individuo) y de un nuevo medio desde el que se actúa (el territorio y no el espacio geométrico de la ciudad), entendidos ambos como matrices de datos geolocalizados.

Por último, en el tercer apartado analizaremos la nueva función del arquitecto-urbanista impuesta por las actuales políticas de regeneración urbana de la OCDE y la Unión Europea (Participatory Planning, Programas Urban I y II, Estrategias de Desarrollo Urbano Sostenible Integrado, EDUSI), consistente en la adecuación socioterritorial del medio orientada a lograr una autogestión productiva del espacio urbano por parte de su propia población, lo que hace que se elimine la resistencia presentada por los individuos a la normalización de sus conductas mediante la puesta en juego de su libertad entendida siempre por Foucault como "el correlato de la introducción de los dispositivos de seguridad". ${ }^{\text {I3 }}$

I2. Foucault, El cuerpo utópico, 57-58.

13. Michel Foucault, Seguridad, territorio y población: curso en el Collège de Francia 1977-1978, trad. Horacio Pons (Buenos Aires: Fondo de Cultura Económica, 2006), 7I. 
Todo ello nos permitirá sostener la vigencia de la arquitectura y el urbanismo como dispositivos gubernamentales de control social y gestión del riesgo presentes en las smart cities y el urbanismo participativo, al mostrar además una tendencia histórica ya percibida por Foucault de desmaterialización o virtualización de las relaciones de visibilidad propia de la tercera era de las mutaciones del espacio identificadas por el autor francés, ${ }^{14} \mathrm{y}$ coincidente con la estética de la desaparición y la lógica paradójica de la imagen descritas por Virilio. ${ }^{15}$

\section{La arquitecturación disciplinar de la ciudad ${ }^{16}$}

Tanto para el panóptico de Bentham como para los análisis gubernamentales de Foucault, la vigilancia nunca fue un fin en sí mismo orientado a garantizar la tranquilidad de un gobernante soberano, sino una estrategia dirigida a la inculcación de las conductas deseadas, normalmente de tipo productivo. ${ }^{17}$ A este respecto, Foucault afirma que "hay que cesar de describir siempre los efectos de poder en términos negativos: 'excluye', 'reprime', 'rechaza', 'censura', 'abstrae', 'disimula', 'oculta'. De hecho, el poder produce; produce realidad; produce ámbitos de objetos y rituales de verdad”. ${ }^{18}$

I4. Según Foucault, mientras que el espacio de la Edad Media se configuraba como un "conjunto jerarquizado de lugares [...] donde las cosas se encontraban colocadas" (Michel Foucault, "Espacios otros: utopías y heterotopías", Carrer de la ciutat, núm. I [1978]: 8) (paradigma de la localización), y la concepción espacial del poder disciplinar se definía como punto inmaterial de una trayectoria (paradigma del entendimiento) que rechaza toda creencia en el espacio como sustancia ontológica, en la actualidad, el espacio se configuraría principalmente mediante "series, árboles, tramas [...] almacenamiento de información [...] identificación de elementos marcados o codificados, en el interior de un conjunto dado" (Foucault, "Espacios otros", 8) (paradigma del emplazamiento). Esto es, como una matriz de datos.

I5. Paul Virilio, The Vision Machine (Bloomington: Indiana University Press, 1994).

I6. Para no alargar excesivamente la extensión del texto dejaremos de lado las consideraciones sobre el poder soberano, cuya perduración en nuestras sociedades ha conocido una transformación muy importante. Michel Foucault, Las redes del poder, trad. Fernando Crespo (Buenos Aires: Prometeo Libros, 20I4), 54 y Michel Foucault, Estrategias de poder, Obras esenciales, trads. Fernando Álvarez-Uría y Julia Varela, vol. II (Barcelona: Paidós, 1999), 299.

17. Michel Foucault, El poder psiquiátrico. Curso en el Collège de Francia 1973-1974, trad. Horacio Pons (México: Fondo de Cultura Económica, 2007); Michel Foucault, Los anormales. Curso en el Collège de Francia 1974-1975, trad. Horacio Pons (México: Fondo de Cultura Económica, 2007); Michel Foucault, La Société punitive, Cours au Collège de France 1972-1973 (París: Gallimard, 2013). I8. Foucault, Vigilar y castigar, 198. 
Desde esta perspectiva conductista-productivista, no sólo las cárceles sino la práctica totalidad de las tipologías arquitectónicas desarrolladas a partir del siglo XVII se configuran como dispositivos para el control visual de sus usuarios. ${ }^{19}$ A este respecto, el análisis formal y espacial de las tipologías arquitectónicas con las que se diseñaron la mayor parte de los equipamientos públicos de los siglos XVII al XIX como dispositivos disciplinarios fue un tema ampliamente tratado por varios de los grupos de estudio con los que colaboraba el propio Foucault, por ello no consideramos necesario insistir en este tipo de cuestiones. ${ }^{20}$

Por el contrario, nuestro interés se centrará en el diseño de la ciudad y el espacio urbano. Dentro de esta nueva escala de estudio, la puesta en marcha del poder disciplinar exige renunciar definitivamente al concepto medieval de ciudad entendida como excepción espacial que asegura el ejercicio de los derechos cívicos y la autoorganización burguesa frente al sistema feudal y el poder soberano, ${ }^{2 \mathrm{I}}$ y comenzar a concebirla como una máquina de normalización y domesticación de los individuos. Desde este punto de vista, Foucault analiza dos diseños de ciudades que con anterioridad al panóptico de Bentham evidencian las características básicas de la arquitectura como técnica disciplinaria: la ciudad de Richelieu y Les Salines de Chaux de Ledoux.

En lo que respecta a la ciudad de Richelieu, pequeño chateaux medieval heredado y convertido por Richelieu en palacio donde recibir al rey y la corte en 1620 , Foucault comenta que la "jerarquización, la comunicación exacta de las relaciones de poder y los efectos funcionales específicos de esa distribución" se orientan de forma unívoca con vistas a "arquitecturar el espacio". ${ }^{22}$

I9. De ahí que el francés se cuestione si “¿puede extrañar que la prisión se asemeje a las fábricas, a las escuelas, a los cuarteles, a los hospitales, todos los cuales se asemejan a las prisiones?”. Foucault, Vigilar y castigar, 230.

20. Entre ellos destaca la colaboración de Foucault con el Centre d'Etudes, de Recherche, et de Formation Industrielle dirigido por Guattari, el Groupe d'Information sur les Prisons en el que también militaba Deleuze, y el grupo de estudios sobre el hábitat dirigido por él mismo (Alliaume et al., 1977).

2I. Max Weber, La ciudad, trads. Julia Varela y Fernando Álvarez-Uría (Madrid: La Piqueta, 1987). Concepción ésta que ha vuelto a hacer su aparición una vez más de la mano de los comunes urbanos (Elinor Ostrom, Governing the Common: The Evolution of Institutions for Collective Action [Edimburgo: Cambridge University Press, 1990]; madrilonia.org, La carta de los comunes. Para el cuidado y disfrute de lo que todos es [Madrid: Traficantes de Sueńos, 20II] y de la nueva reivindicación del derecho a la ciudad definido por Henri Lefebvre (Álvaro Sevilla Buitrago, ed., Espectros de Lefebure, Urban. Revista del Departamento de Urbanistica y Ordenación del Territorio (201I): 3-6.

22. Foucault, Seguridad, territorio y población, 36. 
Ahora bien, ¿qué quiere decir Foucault con "arquitecturar" el espacio? Fundamentalmente se refiere al hecho de que las ciudades no se concebían "a partir de algo más grande que ellas, el territorio, sino a partir de algo más pequeño, una figura geométrica que es una suerte de módulo arquitectónico”. ${ }^{23}$

Módulos, tipologías y ejes de simetría se establecen como las herramientas geométricas operativas para una arquitecturación que siempre implica la distribución jerárquica de las instituciones políticas, los equipamientos y los espacios públicos (plazas y boulevares). ${ }^{24} \mathrm{El}$ espacio urbano se geometriza directamente como proyección de la jerarquía social y política en virtud de unidades de composición (tipologías) en libre disposición sobre un espacio abstracto que funciona a modo de tabula rasa sin ninguna consideración de lo preexistente (fig. I).

El paradigma del urbanismo disciplinario entiende la ciudad como una gran tipología o máquina arquitectónica perfectamente reproducible en cualquier otro lugar. Debido a ello, en Richelieu no se plantea aún la cuestión de la mediación con la ciudad ya construida, esto es, con las relaciones sociales preestablecidas. Según Foucault, la disciplina construye modelos y dispositivos de organización social puros cuya racionalidad radica únicamente en sí mismos, y no en la relación o incidencia sobre relaciones preestablecidas. El poder disciplinario no media, produce de manera directa. ${ }^{25}$

El segundo ejemplo presentado por Foucault como propio de la episteme disciplinar, Les Salines de Chaux, se comenta en Vigilar y castigar junto al panóptico de Bentham como una anticipación de este último en el ámbito fabril. Al igual que en Richelieu, la elección del mismo como paradigma del urbanismo disciplinar se debe a la concepción de su proyección ex nibilo, es decir, a la ideación de una tipología de control social sin mediación alguna con las relaciones sociales preexistentes en una ciudad consolidada (figs. 2a-b y 3 ).

Híbrido entre ciudad y fábrica, Les Salines interesan a Foucault puesto que "a medida que aumentan el número de los obreros y la división del trabajo, las

23. Foucault, Seguridad, territorio y población, 35 .

24. Concretamente, el trazado de Lermercier, realizado en I631, distribuía (siempre de forma subordinada al palacio) una iglesia, un colegio, un tribunal de justicia y dos plazas de 90 metros de lado que marcan el inicio y el fin de un eje de 34 metros de ancho orientado de norte a sur (la grand rue), y a cuyos flancos se situaban las 28 casas grandes de los principales dirigentes de la ciudad.

25. Michel Foucault, El poder, una bestia magnifica. Sobre el poder, la prisión y la vida, trad. Horacio Pons (Buenos Aires: Siglo XXI, 2012), 202. 


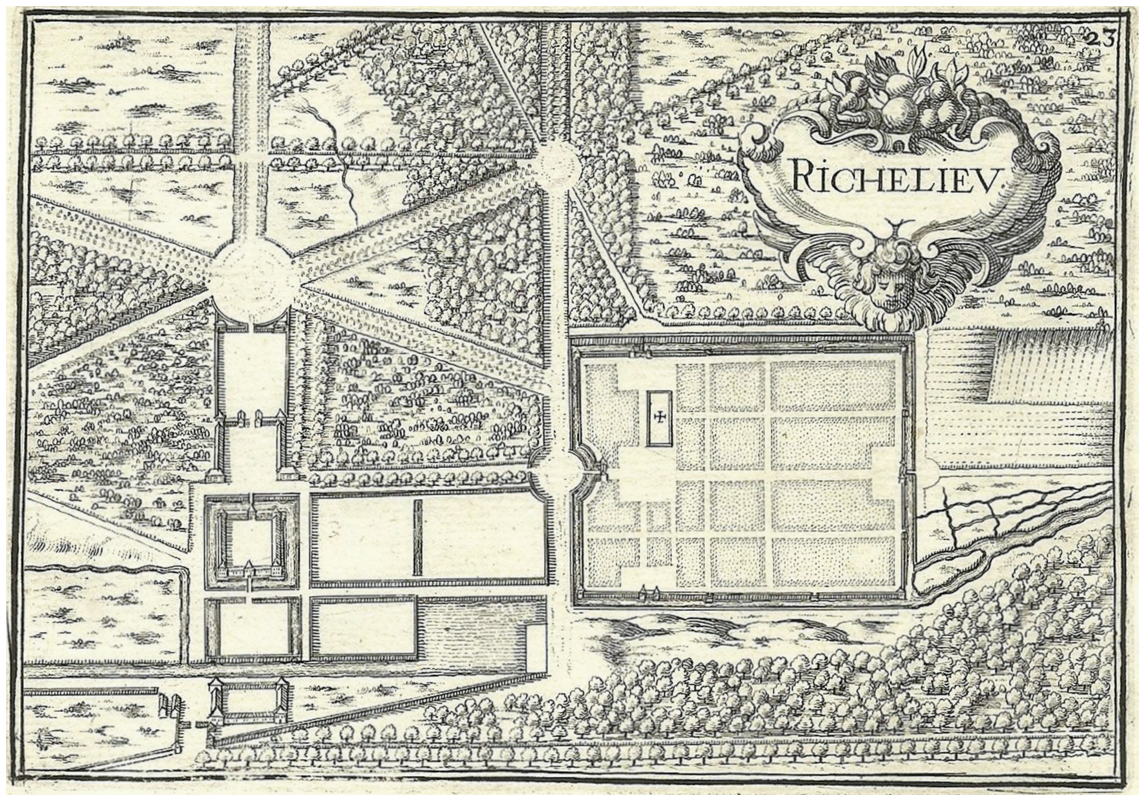

I. Christopher Nicolas Tassin, Plano de la ciudad de Richelieu, I634, placa de cobre sin color, I0.5 $\times 15 . \mathrm{I} \mathrm{cm}$, tomada de Les Plans et Profils de toutes les principals villes et lieux considerable de France. Ensemble les cartes generals de chacune province \& les particulieres de chaque government d'icelles. Par le Sieur Tassin Geographe ordinaire de la Majesté (París: Melchior Tavernier, I634), s.n.

tareas de control se hacen más necesarias y más difíciles". ${ }^{26}$ Les Salines suponen un avance respecto a Richelieu desde el punto de vista de la promoción del productivismo de las técnicas disciplinarias. Por ello, pese a que la gran escala de actuación de Les Salines no permite un control panóptico pleno debido a las limitaciones ópticas de la época, ello no impide que el panoptismo se configure como leitmotiv del proyecto hasta el punto de que las teorías clásicas de composición arquitectónica se sacrifican con el fin de lograr la distribución visual más adecuada de los pabellones. ${ }^{27}$

26. Foucault, Vigilar y castigar, 179.

27. A este respecto, Vidler comenta que "al describir su planta salina, Ledoux insiste en lo que él considera como virtud principal del semicírculo: su capacidad para facilitar lo que llama vigilancia [...] La visión sin obstáculos, facilitada por el arquitecto, representaba la respuesta de Ledoux al complejo sistema de control administrativo, al trabajo y a la productividad exigidos por el código de las salinas reales". Anthony Vidler, Ledoux (Madrid: Akal, 1994), 50. 

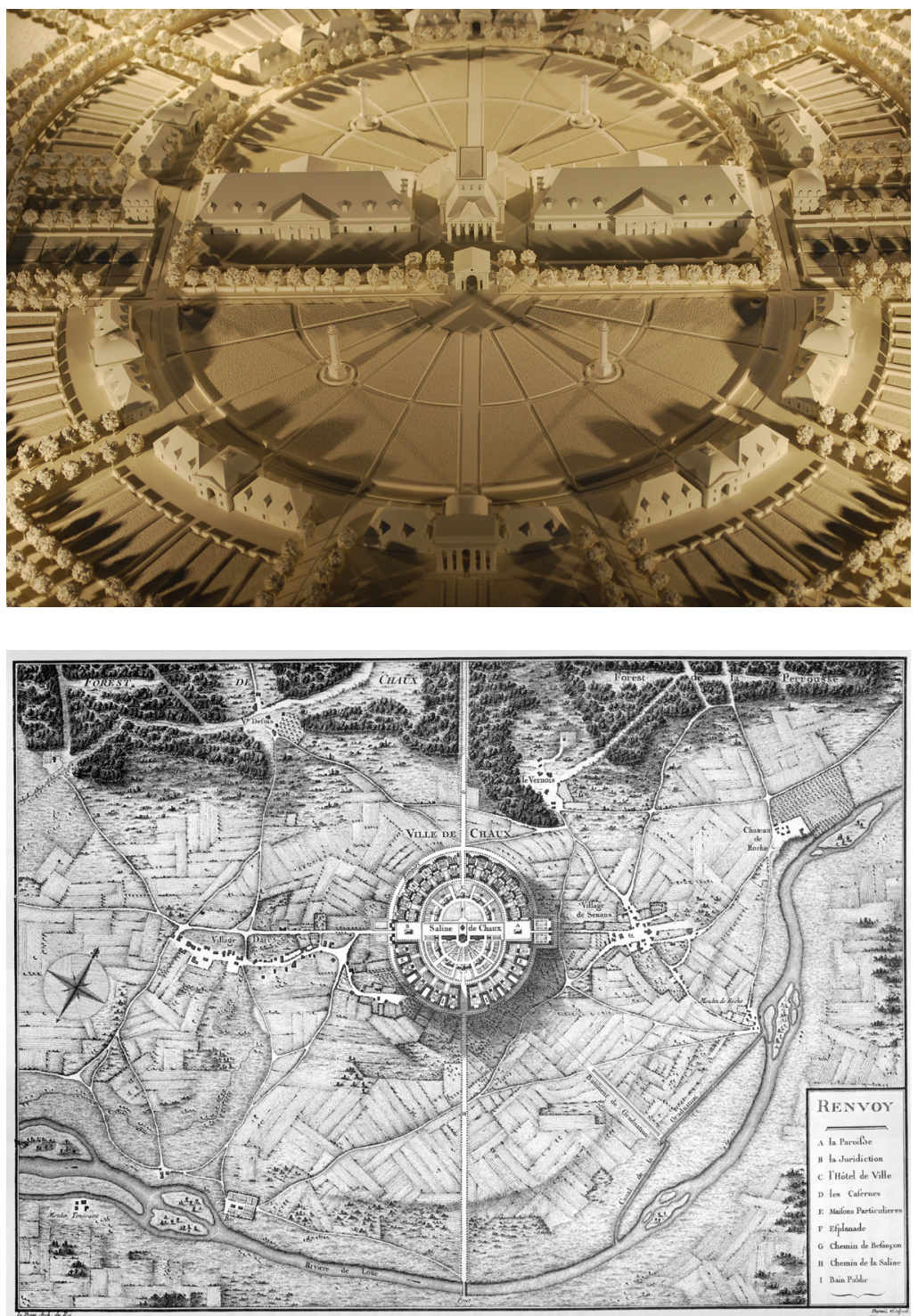

2a) Vista aérea de Les Salines de Chaux, Musée Architecture Ledoux. Foto: Arnaud 25, CC BY-SA 4.O; 2b) "Carte générale des environs de la Saline de Chaux" Planche I4 de "L’architecture considérée sous le rapport de l'art, des moeurs et de la législation", París, I804. CC O I.O 
I92 JORGE LEÓN CASERO / JULIA URABAYEN

Pero la fábrica de Les Salines, al igual que el panóptico de Bentham, no es únicamente la concepción de una tipología edificatoria concreta para la vigilancia de sus habitantes sino, antes que nada, un dispositivo gubernamental para la producción de unos sujetos concretos, productivos y domesticados. Por ello los dispositivos reguladores de Les Salines se proyectaron tanto dentro como fuera de los límites propios del trabajo de la fábrica. También "el periodo de ocio está funcionarizado en aras de la productividad" ${ }^{28}$ En última instancia, de lo que se trata es de "formar un proletariado pacífico, moralizado, lo bastante robusto como para trabajar y lo suficientemente feliz como para estar satisfecho". ${ }^{29}$

Este proyecto de modificación de las conductas de los individuos mediante el diseño de su hábitat será precisamente el punto de paso del urbanismo disciplinar al biopolítico, si bien la principal diferencia entre ambos estribará en que mientras que el urbanismo disciplinar proyectaba máquinas urbanas ex nibilo para la normalización de las conductas de los individuos, el urbanismo biopolítico partirá del estudio científico de las relaciones sociales preexistentes, lo que culminará con la construcción de un nuevo objeto de gobierno: la población.

Ahora bien, una de las razones principales que llevan a desarrollar el urbanismo biopolítico consiste en el fracaso mostrado por el urbanismo disciplinar para modificar la conducta de los individuos que habitan en ciudades consolidadas que ya han desarrollado una extensa red de relaciones sociales preexistentes, y que no pueden ser normalizados con sus máquinas ex nibilo a menos que se les inserte en las máquinas arquitectónicas una vez que ya es demasiado tarde (criminales en las cárceles, enfermos en los hospitales, entre otros). Los dos ejemplos paradigmáticos de este fracaso, no comentados de forma explícita por Foucault, se pueden encontrar en los proyectos de la Place des Vosgues y la Place Vendôme.

Mientras que en la ciudad renacentista las clases dirigentes habitaban en villas individuales a las afueras de la ciudad, la Place des Vosgues supone el inicio de un proyecto de control disciplinar de la ciudad consolidada mediante "arquitecturaciones" del espacio urbano estratégicamente localizadas. En lo espacial delimitada por medio de la edificación de 38 viviendas destinadas de manera exclusiva a la nobleza, la Place des Vosgues se configura como un espacio separado con nitidez del resto de la ciudad mediante una geometría racional que excluye el tráfico rodado y peatonal de todo aquel que no resida allí,

28. Vidler, Ledoux, 56.

29. Vidler, Ledoux, II9. 


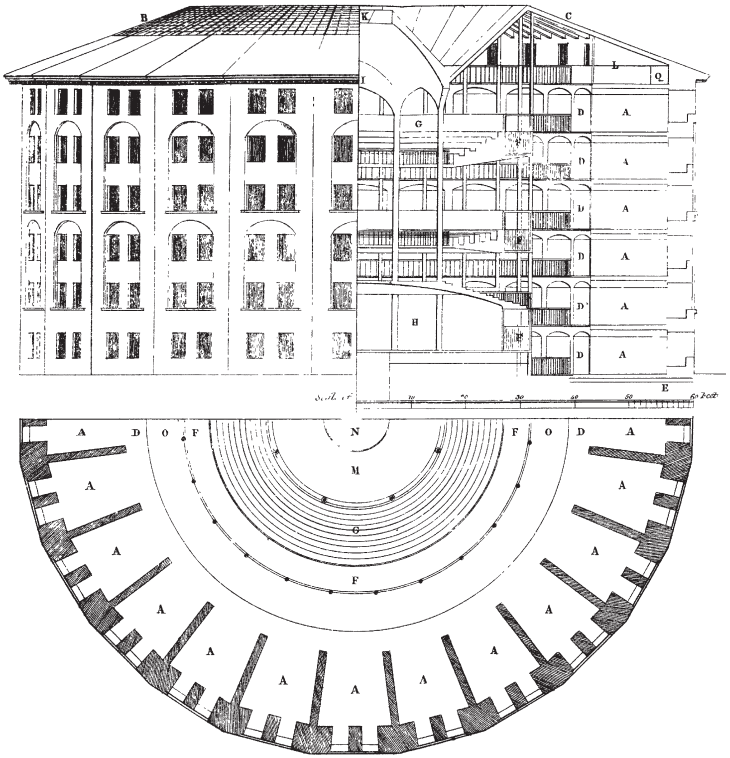

3. Jeremy Bentham, sección y planta del panóptico, tomados de The Works of Jeremy Bentham, published under the Superintendence of his Executor, John Bowring, II vols., vol. 4 (Edimburgo: William Tait, I838-I843), tomado de http://oll.libertyfund. org/titles/1925\#lfo872-04_ figure_oo9

y constituye de este modo uno de los principales hitos en la fragmentación y segmentarización del espacio urbano que pone fin al principio de la continuidad espacial propio de la ciudad medieval (figs. $4 \mathrm{a}$ y b). ${ }^{30}$

En los desarrollos orgánicos de la ciudad medieval, la continuidad del espacio urbano impedía su compartimentación mediante tipologías del espacio público diferenciadas con claridad, por ello las "plazas" eran muchas veces simples ensanchamientos irregulares de las calles. Por su parte, el urbanismo disciplinar barroco utilizó la arquitecturación del espacio público precisamente con el objetivo de segmentarizar y controlar el espacio por medio de discontinuidades en su carácter público, ${ }^{3 \mathrm{I}}$ al instaurar un "sistema de apertura y cierre

30. Leonardo Benévolo, Diseño de la ciudad, volumen III. Arte y ciudad medieval (Barcelona: Gustavo Gili, 1982), 48-5I.

3I. De este modo, las plazas barrocas, en general, y la Place des Vosgues, en particular, pueden leerse como auténticos enclosures urbanos paralelos a los enclosures rurales tan comentados por la teoría de los comunes (Elinor Ostrom, Governing the Commons y Álvaro Sevilla Buitrago, Espectros de Lefebure), el principio de ambos coincide sintomáticamente con su inicio en el siglo XVII. 
DOI: http://dx.doi.org/10.22201/iie.18703062e.2018.112.2634

194 JORGE LEÓN CASERO / JULIA URABAYEN

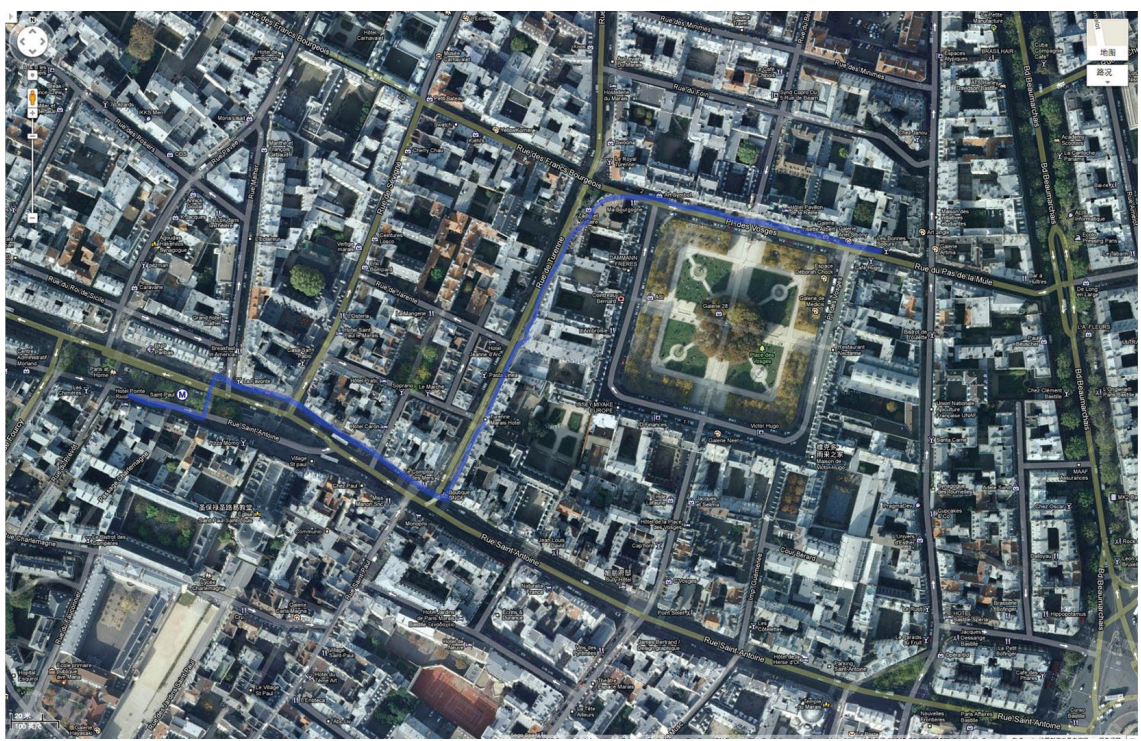

4a) Vista aérea de la Place des Vosges, París, 2002. Google Earth.

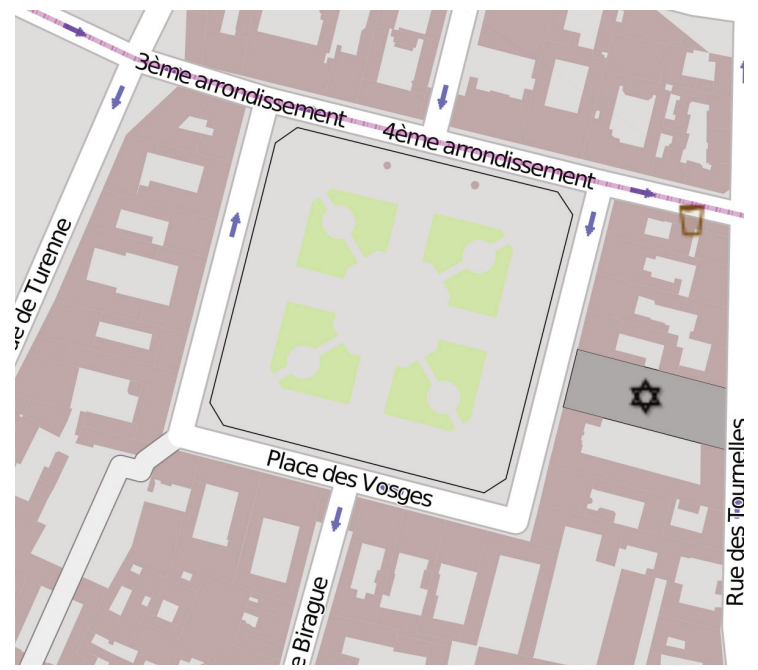

4b) Vista en planta de la Place des Vosges, París. OpenStreetMap CC BY-SA 4.O. 
que aísla respecto al espacio circundante".$^{32}$ De este modo, la plaza, en lugar de concebirse como una tipología de espacio público tal y como la entendemos en la actualidad, funcionó como uno de los dispositivos de control social por excelencia del urbanismo disciplinar.

Pero mientras que en Richelieu o la Place des Vosgues la distribución de las interrupciones del espacio público se realizaba de forma directa para localizar la zona residencial de la clase dirigente en función de su proximidad a las principales tipologías institucionales (equipamientos) y de espacio público (la grand rue), tanto en el proyecto de Mansart para la Place Vendôme como en todos los sucesivos proyectos de espacios urbanos desarrollados en Londres tras el incendio de 1666,33 no existe ya adjudicación directa de la zona residencial determinada a priori por el proyecto urbanístico, sino que ésta se deja a la educada libertad de los gobernados en el mercado. Así pues, el espacio urbano se continúa arquitecturando, pero la zonificación espacial y la segregación social de la ciudad ya no obedece a una imposición política directa, sino que es libremente decidida por una actuación de los individuos orientada a "materializar el valor urbanístico potencial del suelo en un área urbana en expansión" (figs. 5a y b). ${ }^{34}$

La técnica de control social de la población, aun dentro del paradigma disciplinar, ya no se basa en una planificación determinista y completa del espacio urbano, sino únicamente en la distribución espacial de los elementos estratégicos (tipologías delimitadas de espacio público y de instituciones) ${ }^{35}$ que hacen subir el precio del suelo. Por lo que sólo la clase dirigente puede residir en esa zona arquitecturizada. En otras palabras, las técnicas de gobierno de la ciudad han pasado de la organización y zonificación directa de su espacio urbano a la adecuación del medio socioeconómico que lo determina.

Por último, aunque no sea uno de los temas estudiados directamente por Foucault, el caso del urbanismo colonial latinoamericano anterior al siglo XIX es uno de los mejores ejemplos del carácter de dispositivo disciplinar de producción presente en las ciudades planificadas por los colonos durante este periodo. Su morfología urbanística se codificó por Felipe II con la ley de 1573,

32. Foucault, El cuerpo utópico, 27-28.

33. Bloomsbury Square, St James's Square, Soho Square, Red Lion Square o las plazas de Mayfair, entre otros.

34. Anthony E. J. Morris, Historia de la forma urbana: desde sus origenes hasta la revolución industrial, trad. Reinald Bernet (Barcelona: Gustavo Gili, 1984), 222.

35. En el caso concreto de la Place Vendôme las instituciones proyectadas fueron la Biblioteca Nacional, la Real Casa de la Moneda y las residencias para los embajadores extranjeros. 
DOI: http://dx.doi.org/10.22201/iie.18703062e.2018.112.2634

196

JORGE LEÓN CASERO / JULIA URABAYEN

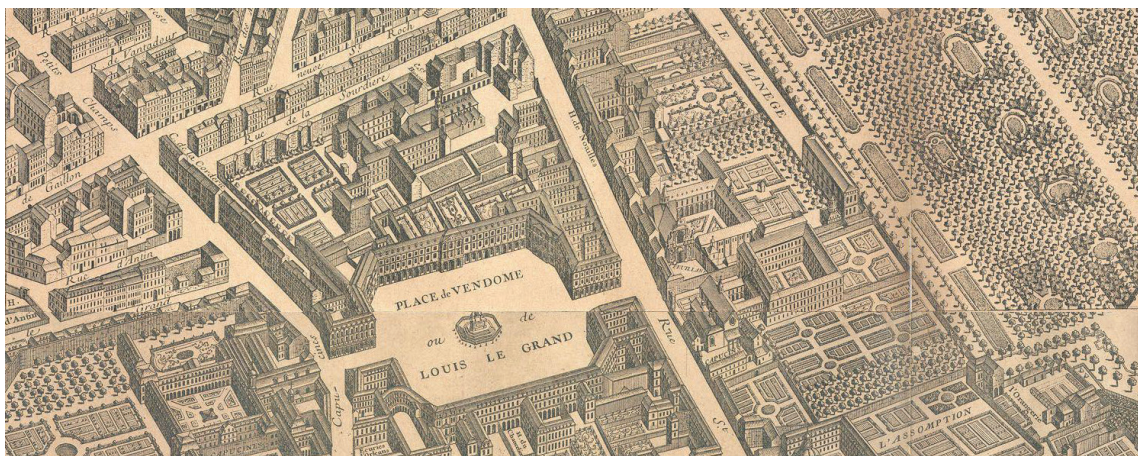

5a) Louis Bretez, representación de la Place Vendôme, detalle de la plancha Is y ig del Plan Turgot de París, grabado (aguafuerte y buril), I739, $32.5 \times 48.7$ cm, París, Geographicus Rare Antique Maps. Foto: cc or.o.

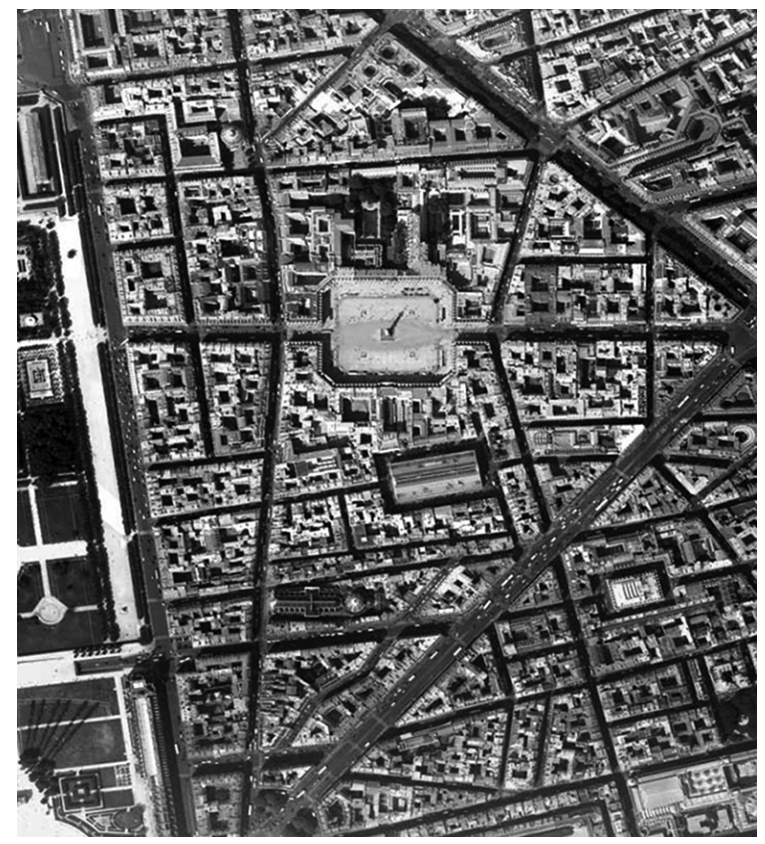

5b) vista en planta de la

Place Vendôme, París, 2012. Imagen Google Earth. 
que prescribía las características básicas de su diseño: calles rectilíneas y ortogonales, manzanas iguales (casi siempre cuadradas) y una plaza en el centro de la ciudad resultado de la fusión de algunas manzanas donde se ubicaba la iglesia, el palacio municipal y las casas de los mercaderes y colonos ricos. ${ }^{36}$ Una vez realizado el replanteamiento del suelo, se asignan las parcelas donde los propietarios podrán construir las edificaciones con fondos propios: el poder público define la morfología de la ciudad como forma a priori y los propietarios privados edifican en virtud de sus posibilidades.

A diferencia de las ciudades europeas de los siglos XV-XIx, la mayor parte de las ciudades coloniales latinoamericanas se construyen sin murallas ni fosos (salvo los puertos marítimos estratégicos), prima la posibilidad de crecimiento en todas direcciones sobre la defensa militar, y se atenuá la diferencia entre campo y ciudad. Mientras que en la morfología de las ciudades europeas aún prevalecía en la arquitecturación de espacios finitos susceptibles de ser controlados panópticamente, las ciudades coloniales latinoamericanas — concebidas más como un puro dispositivo de dominación territorial y gestión de recursos naturales que exportar a Europa que como máquinas de disciplinar individuos concretos-, se pondrán mucho más énfasis en las infraestructuras de comunicación y por ello constituyen de este modo uno de los primeros casos de urbanismo biopolítico olvidados por los intelectuales que, como Foucault, se centran exclusivamente en el estudio de Europa y prescinden del de las colonias. El urbanismo colonial latinoamericano fue, por tanto, el banco de pruebas necesario para que pudiera desarrollarse la gobernanza biopolítica europea (figs. 6 y 7 ).

\section{Biopolítica I: la gestión urbanistica de la población como matriz de datos}

Desde el punto de vista de la gubernamentalidad biopolítica, Foucault afirma que "ya no se trata en absoluto de construir dentro de un espacio vacío o vaciado, tal cual sucedía en esas ciudades disciplinarias”, ${ }^{37}$ sino que el horizonte de

36. Este mismo modelo se aplicará por franceses e ingleses en los siglos XVII y XvIII en la colonización de América del Norte: se concebirá la retícula como un instrumento aplicable a cualquier escala y ámbito, aprovechable tanto para la planificación de ciudades como para la parcelación rural promovida por Jefferson entre otros.

37. Foucault, Seguridad, territorio y población, 38. 


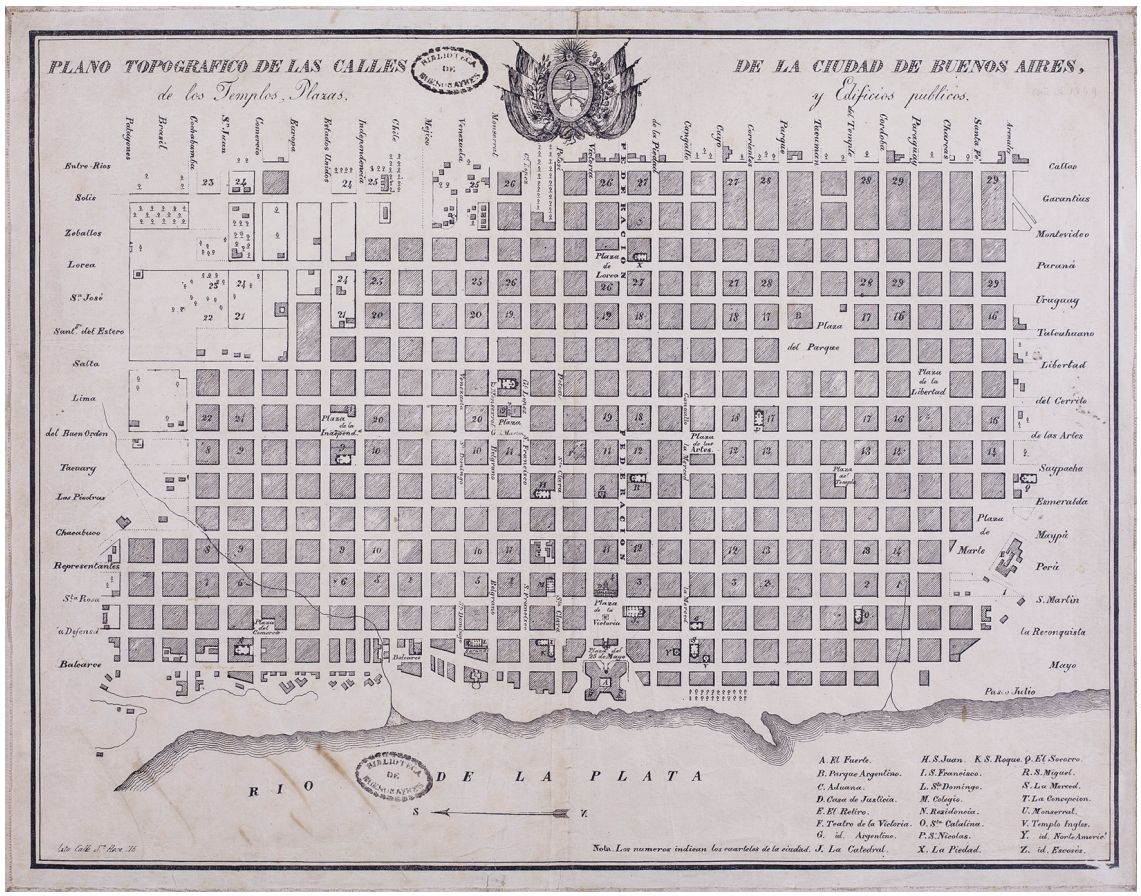

6. Anónimo, Plano topográfico de las calles de la ciudad de Buenos Aires, de los templos, plazas y edificios públicos, $34 \times 43 \mathrm{~cm}$, siglo XIX, Biblioteca Pública Nacional Mariano Moreno, Argentina.

sentido abandona el paradigma del control (vigilancia) y pasa al de seguridad o "gestión del riesgo". ${ }^{8}$

Frente a la primacía del trabajo de arquitecturación del urbanismo disciplinar, el paradigma de gestión del riesgo biopolítico apostará por el empleo de la estadística como técnica de control, ya no de las conductas individuales, sino de la población en su conjunto, entendiendo esta última como "un dato depen-

38. Sintomáticamente, esta "gestión del riesgo" es la denominación empleada por la mayor parte de los manuales de Derecho Administrativo para referirse al nuevo paradigma de funcionamiento de las administraciones públicas frente al "mantenimiento del orden" propio del Estado policial decimonónico o la gestión directa de los servicios públicos por parte del Estado social. José Esteve Pardo, Lecciones de Derecho Administrativo (Madrid: Marcial Pons, 2013), 51. 


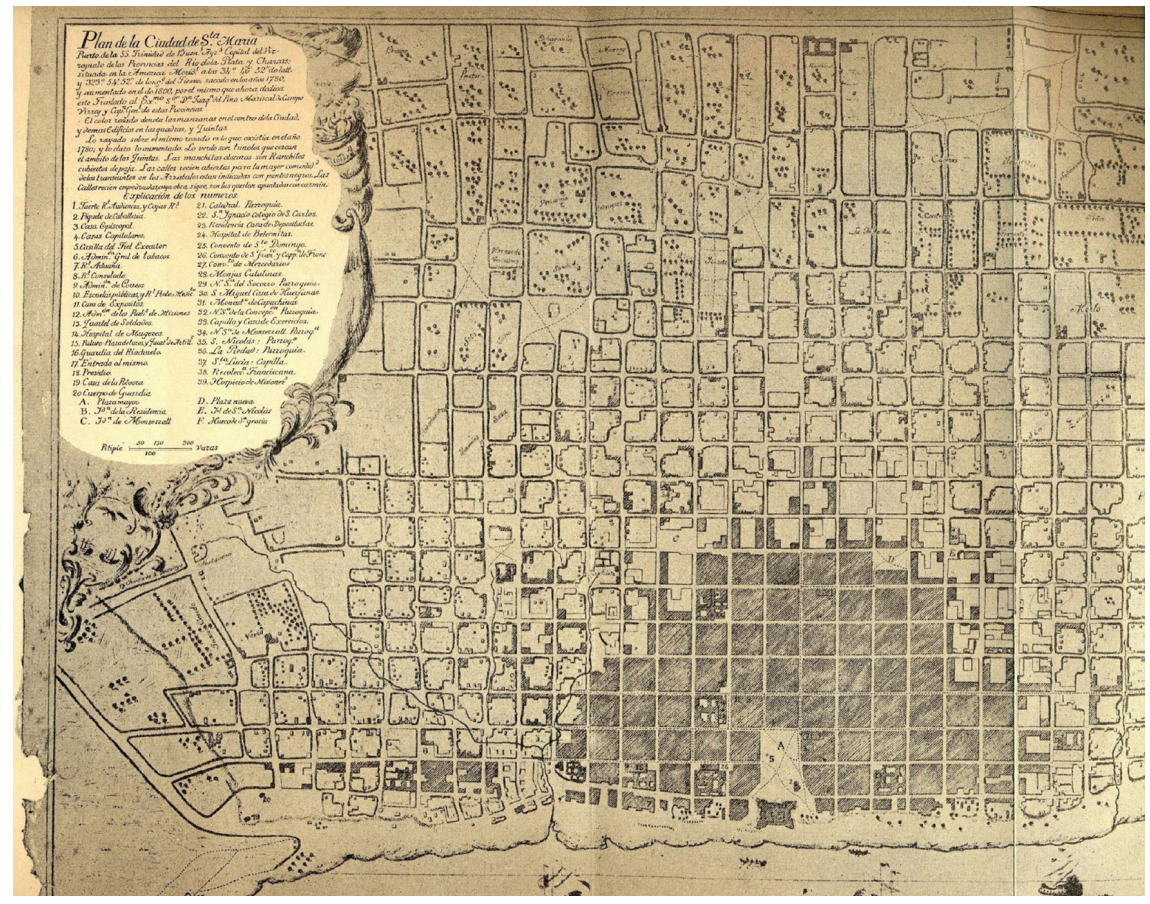

b)

7. Martín de Boneo, Plan de la Ciudad de Sta. María, ca. I780-I800. Foto: atlasarchivo.com.ar.

diente de toda una serie de variables" ${ }^{39}$ Esto es, como un "conjunto de procesos" cuyo modo de aparición, y por tanto de mediación, ya no será el espacio ópticogeométrico, sino la información numérica. Por su parte, "seguridad" será entendida como "la gestión de esas series abiertas", el "cálculo de probabilidades" 40 dentro de una escala de intervención estatal que concibe el espacio urbano como un dato más a gestionar por la nueva técnica paradigmática de administración espacial: la ordenación del territorio. ${ }^{4 \mathrm{I}}$

39. Foucault, Seguridad, territorio y población, 94.

40. Foucault, Seguridad, territorio y población, 40.

4I. Según Foucault, éste es el momento en el que "se deja de percibir la ciudad como un lugar privilegiado, como una excepción en un territorio constituido de campos, de bosques y de rutas. Las ciudades no son ya en adelante islas que escapan al derecho común. De ahora en más, las ciudades, con los problemas que ellas suscitan y las configuraciones particulares que adoptan, sirven de modelos a una racionalidad gubernamental que va a aplicarse al conjunto del territorio" (Foucault, El cuerpo utópico, 86). 
De este modo, la función de la ordenación del territorio ya no consiste en la arquitecturación del espacio óptico sino en la generación de todos esos "dispositivos de seguridad [que] trabajan, fabrican, organizan, acondicionan un medio [...] ámbito en el cual se da la circulación. Es un conjunto de datos naturales, ríos, pantanos, colinas, y un conjunto de datos artificiales, aglomeración de individuos, aglomeración de casas, etc.”. ${ }^{42}$

En primer lugar, estos datos los recopilan las distintas disciplinas académicas agrupadas bajo la nueva ciencia estadística: geografía (física y humana), topografía, cartografía, urbanismo e ingenierías varias, junto a la reconfiguración del derecho como normalización y racionalización procedimental de la Administración Pública, ${ }^{43}$ que configurarán una noción de territorio entendido primordialmente como infraestructura dromológica. Así pues, el paradigma de la visibilidad panóptica de un espacio estático se cambia por el de la aceleración de la circulación de personas y mercancías en un territorio: "La ciudad no será concebida ni acondicionada en función de una percepción estática que asegure la perfección instantánea de su funcionamiento", 44 sino que "nos hallamos en un momento en que el mundo se experimenta, creo, no tanto como una gran vida que se desarrollaría a través del tiempo sino como una red que relaciona puntos y que entrecruza su madeja". ${ }^{45}$ La ciudad ya no es un espacio óptico, sino un nodo más dentro de una red de relaciones que acondiciona un territorio.

Las principales tipologías de intervención dejarán de ser las plazas y el espacio público urbano, que ceden su lugar a la adecuación de los puertos mercantiles y militares realizados por Vauban,${ }^{46}$ el sistema de aduanas proyectado por Ledoux al final de su carrera y el establecimiento de una red territorial de infraestructuras viarias que atravesarán las ciudades al superponer su escala territorial a la escala óptica del espacio urbano.

Si el sistema viario del urbanismo disciplinar se gestionaba mediante la arquitecturación óptico-geométrica del espacio urbano, el urbanismo bio-

42. Foucault, Seguridad, territorio y población, 4I.

43. A este respecto conviene recordar que los primeros desarrollos del Derecho Administrativo en España nacieron en las Escuelas de Ingenieros de Caminos, y no en las facultades de Derecho.

44. Foucault, Seguridad, territorio y población, 39.

45. Foucault, El cuerpo utópico, 63-64.

46. Además de colaborar en diversas obras de ingeniería civil como el canal del Bruche, entre I667 y 1707 Vauban dirigió la construcción de 37 fortalezas nuevas y puertos militares entre los que destacan los de Ambleteuse, Brest, Dunkerque, Quebec, Rochefort, San Juan de Luz (Fuerte Socoa), Saint-Malo, Saint-Martin-de-Ré, Toulon, Wimereux, Le Palais, Le Portel, Sarrelouis. 


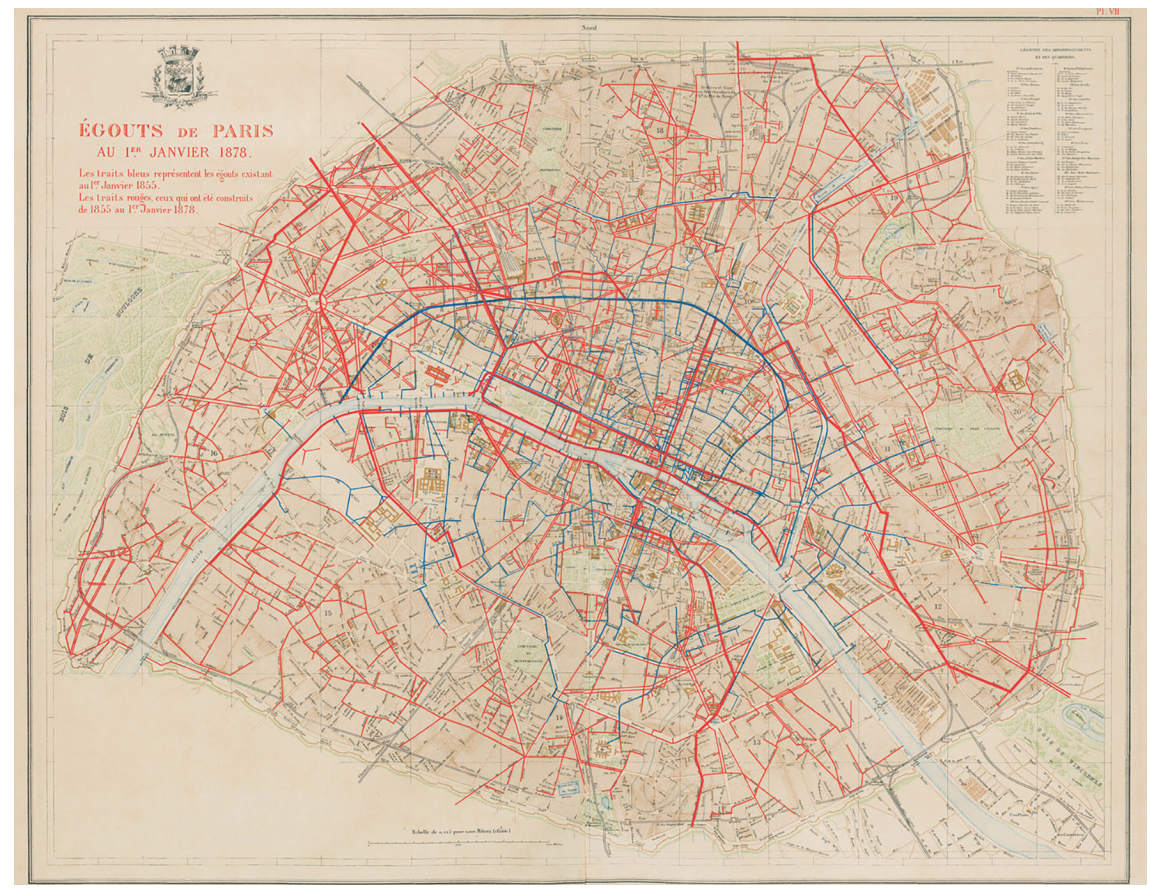

8. Jean-Charles Adolphe Alphand, "Les Travaux de Paris" (París: Imprimerie Nationale, 1889), plate VII. Cortesía de la David Rumsey Map Collection CC BY-NC-SA 3.O.

político desarrollado desde la ordenación del territorio lo concibe como el medio de conexión de los puntos mercantilmente estratégicos de la ciudad con la red territorial de comunicaciones gestionada por administraciones públicas de carácter supramunicipal. Ejemplos de ello son tanto las intervenciones del barón Georges Eugène Haussmann en el París de Napoleón III como el desarrollo de las infraestructuras viarias de las principales ciudades portuarias en Europa, Asia o América desde finales del siglo XviII hasta la actualidad (figs. 8-IO).

De forma paralela, la construcción del nuevo medio que es el territorio estará acompañada de la del nuevo objeto de gobierno que ya no será el individuo, sino la población. Para ello se genera una nueva disciplina que concibe al hombre "en términos de demografía [...] de saber qué relaciones de vecindad, qué tipo de almacenamiento, de circulación, de emplazamiento, de 
clasificación de los elementos deben escogerse preferentemente en tal o cual situación para proporcionar tal o cual fin". ${ }^{47}$

Además, en la actualidad, la clásica toma de datos recopilados por las administraciones públicas para la construcción de la población (padrón municipal, seguridad social, catastro, Hacienda, registro de la propiedad y registro mercantil) se complementa con toda otra serie de datos recopilados por entidades privadas (tarjetas de crédito, cuentas de correo electrónico, redes sociales gratuitas) o público-privadas (índices de contaminación y huella de carbono, sensores de temperatura y humedad, sensores del caudal de flujos) que han llevado el horizonte de sentido anunciado por Foucault a un desarrollo exponencial que ha culminado en la conformación de las smart cities: auténticas máquinas automatizadas e hiperespecializadas en la toma y gestión de datos, así como en la identificación de medidas concretas dirigidas a la optimización de la circulación de personas, mercancías e información. ${ }^{48}$

A este respecto, cobra una importancia especialmente relevante la capacidad existente para promover una continua reconfiguración del medio a gestionar mediante el cruce de datos. Por ello uno de los cambios más importantes introducidos por las nuevas smart cities en lo concerniente a la ordenación del territorio y la población analizadas por Foucault ha consistido en llevar la capacidad de registro y gestión de datos con los cuales proceder a la adecuación infraestructural del medio a una readaptación continua e informatizada en tiempo real. Ello ha promovido que la desaparición del espacio óptico-geométrico propio del urbanismo disciplinar coincida con la aparición de un nuevo espacio virtual que ha vuelto obsoletas las técnicas clásicas de la ordenación del territorio. En palabras de Deleuze, "el mundo moderno es aquel donde la información suplanta a la naturaleza”. ${ }^{49}$

47. Foucault, "Espacios otros", 9.

48. Un aspecto importante, y que hay que aclarar, es que aunque se ha producido un incremento notable de las cámaras de vigilancia tanto en el interior de las tipologías arquitectónicas más tradicionales como en el espacio público de las ciudades, ello no es un argumento a favor de un supuesto retorno a la lógica disciplinar del poder como paradigma gubernamental. En realidad, las ciudades no se gestionan desde las cámaras de vigilancia, sino que la información que éstas puedan suministrar forma parte, como un paquete más, de toda una matriz de datos con la que se construye el modelo concreto de cada población. Las smart cities no son dispositivos disciplinares teledirigidos, sino dispositivos de codificación del medio y la población.

49. Gilles Deleuze, La imagen-tiempo. Estudios sobre cine 2, trad. Irene Agoff (Barcelona: Paidós, 1987), 356. 
DOI: http://dx.doi.org/10.22201/iie.18703062e.2018.112.2634

ESPACIO, PODER Y GUBERNAMENTALIDAD

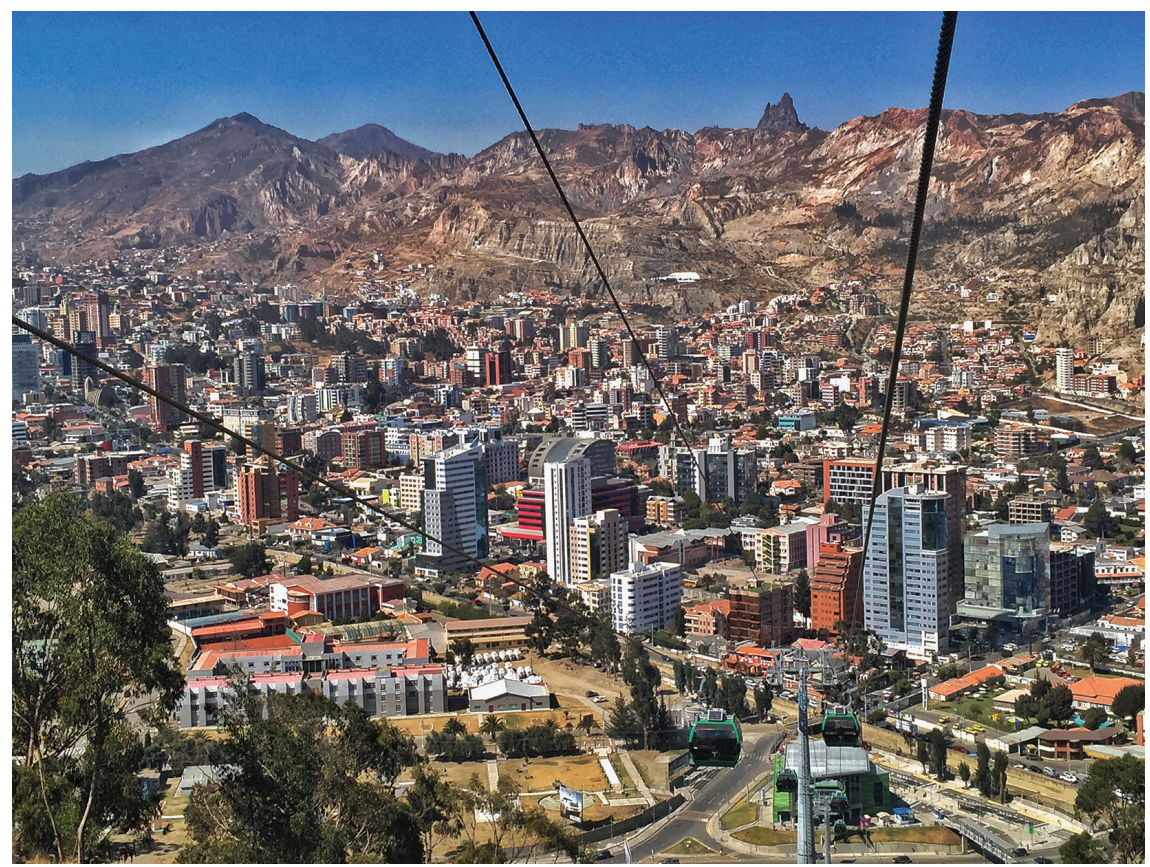

9. Vista aérea de La Paz, Bolivia, 2004. Foto: Russland, C.C: BY SA 4.O.

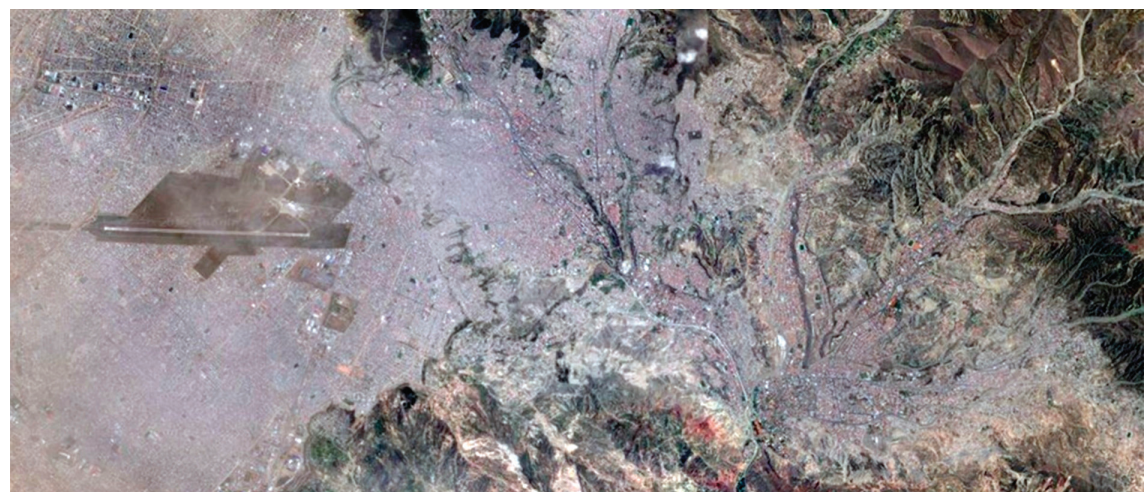

Io. Vista en planta de El Alto, Bolivia. Google Earth. 
Según esta nueva concepción, el modelo paradigmático de urbanismo biopolítico no sería tanto una tipología concreta de espacio urbano como un tipo de programa informático que vincule la información disponible con su geolocalización; un tipo específico de software que en la actualidad denominamos sistemas de información geográfica. Desde este punto de vista, destacan dos experiencias piloto de programas informáticos concebidos por el despacho de arquitectura MVRDV junto a cThrough, que si bien no se desarrollaron suficientemente ni se publicitaron como para llegar a convertirse en una herramienta operativa de gestión urbanística en el mercado, sí que permiten delinear con claridad el horizonte de sentido al que ha llegado la concepción de los nuevos modelos de gubernamentalidad biopolíticos en lo referente a la planificación urbanística como técnica de gestión de poblaciones.

Tanto en el programa RegionMaker ${ }^{50}$ como en Spacefighter. The Evolutionary City Game ${ }^{\text {sI }}$ el urbanista biopolítico, conectado en tiempo real a la mayor parte de las bases de datos disponibles a través de Internet, accede a un simulador que, al trabajar con estadísticas y cartografía real, logra (pre)ver a corto-mediano plazo las consecuencias económicas, ecológicas o sociales (en parámetros de densidades, población, precios del suelo, entre otros), que una determinada actuación urbanística conllevaría sobre dicha matriz de datos.

Si la principal limitación de RegionMaker radicaba, al igual que en el caso de las administraciones públicas en los siglos XIX y XX, en su consideración de programa cerrado en el que el sistema de relaciones entre diversas estructuras venía dado; Spacefighter, en cambio, diseñado en colaboración con cThrough, al dar la oportunidad a los usuarios de todo el mundo (el programa se colgó en la red) que hayan demostrado por medio de su empleo un nivel de conocimientos considerado apto, de poder cambiar, adaptar o añadir nuevas programaciones a las ya propuestas, permite una continua reelaboración y una progresiva readaptación y reprogramación del medio en tiempo real.

La principal innovación de esta visión del papel del urbanista biopolítico radica en que dichos programas no se conciben como meras herramientas de análisis que ayudan al arquitecto a obtener un diseño formal optimizado. La forma arquitectónica no juega ningún papel ahí. En lugar de constituirse como simple "elemento de sostén, que asegura cierta distribución de la gente en el espacio [...] así como la codificación de las relaciones que mantienen

50. MVRdV, KM3. Excursions on Capacities (Barcelona: Actar, 2005).

5I. MVRDV-DSD, Spacefighter. The Evolutionary City Game (Barcelona: Actar, 2007). 
entre ellos" ${ }^{\prime 2}$ en la que se detuvieron los análisis de Foucault, el urbanista biopolítico empieza por fin a ver que "el arquitecto no es un hombre de dibujos". 53

\section{Biopolitica II: el autocontrol participativo de la población}

El paradigma propio de las smart cities como ciudades biopolíticas ha fundido en una única matriz de datos indistinguible territorio y población, por lo que a partir de ahora, las técnicas de intervención y regeneración urbana deberán desarrollar estrategias que aúnen en un solo proyecto de intervención técnicas de adecuación del medio territorial y del medio socioeconómico.

Puesto que "la arquitectura [...] no constituye tan sólo un elemento del espacio [sino que] está precisamente pensada como inscrita en un campo de relaciones sociales, en cuyo seno ella introduce cierta cantidad de efectos específicos", 54 el papel del arquitecto-urbanista biopolítico tiende cada vez más a dejar de ser el de diseñador del espacio óptico-geométrico de la ciudad para empezar a constituirse como el "intermediario entre los usuarios, los promotores, las autoridades políticas y los financieros". 55

A este respecto, los principales hitos del nuevo urbanismo biopolítico son las políticas de regeneración urbana desarrolladas por la Unión Europea a partir de los programas Urban y el enfoque mantenido por la OCDE en su informe Distressed Urban Areas durante la década de los noventa. Por medio de ellos, el acondicionamiento infraestructural del medio llevado a cabo por las smart cities se complementa con un acondicionamiento jurídico-administrativo del mismo orientado a la búsqueda de sinergias con la economía de libre mercado y la consolidación y legitimación de los aparatos políticos de poder mediante la búsqueda del consenso y la participación integral de la sociedad.

El origen de las iniciativas Urban ha sido habitualmente identificado con la adaptación realizada desde la Unión Europea del programa británico City Challenge desarrollado en I99i por el Department of Environment de la ciudad de Londres. El objetivo fundamental de dicho programa radicaba en la atracción de inversión privada mediante el fomento de la cultura empresarial local por

52. Foucault, El cuerpo utópico, IO6.

53. Henri Lefebvre, "La producción del espacio", Revista de Sociología, núm. 3 (1974): 225.

54. Foucault, El cuerpo utópico, Io6.

55. Lefebvre, "La producción del espacio", 225. 
medio de la conformación de coaliciones público-privadas entre las autoridades locales y los diversos agentes y entidades con intereses en el área de actuación. ${ }^{56}$

El diseño de la iniciativa comunitaria, realizado por Michael Parkinson a petición de la Dirección General de Política Regional de la Comisión Europea, estableció seis elementos básicos: I) enfoque area-based; 2) estrategia a mediano plazo (5-6 años); 3) enfoque integrado; 4) implicación del sector público, privado y la comunidad local; 5) colaboración entre diversos niveles de gobierno y distintos departamentos del mismo nivel, y 6) proceso de selección competitivo. Se trata de una propuesta posteriormente descrita como el resultado de "sumar al modelo británico una [...] base más social", 57 que aunaba la postura francesa sobre la "exclusión social y cultural" con la británica más centrada en la "exclusión material". ${ }^{88} \mathrm{Al}$ menos en teoría, la propuesta europea apostaba por un fortalecimiento de la capacidad institucional local que lograse "acercar a distintos actores y propiciar su conocimiento mutuo" de cara a conseguir "la devolución del poder a la comunidad y los actores locales y su corresponsabilidad en la toma de decisiones (empoderamiento)".59 En la actualidad, la estrategia de los programas Urban sigue vigente mediante los concursos bianuales de urbanismo Europan y las Estrategias de Desarrollo Urbano Sostenible Integrado (EDUSI), financiadas con más de IOoo millones de euros de los fondos FEDER y todavía en fase de tramitación por parte de la Unión Europea.

En lo que se refiere a los Europan, las seis últimas ediciones de los mismos se han adaptado a la filosofía gubernamental iniciada con los programas Urban, al

56. Claus Faber, "Consider the View that the City Challenge Initiative Represents a Fundamental Realignment in Urban Policy", Curso Urban Regeneration in Britain de Lawless, 1994, consultado el 30 de enero de 20I7, en http://www.clausfaber.net/uploads/media/citychallenge.pdf.

57. Sonia De Gregorio, "Políticas urbanas de la Unión Europea desde la perspectiva de la planificación colaborativa. Las iniciativas comunitarias Urban I y Urban II en España”, Cuadernos de Investigación Urbanistica, núm. 98 (2015): 20.

58. Rowan Atkinson, "Combating Social Exclusion in Europe: The New Urban Policy Challenge”, Urban Studies 37, núms. 5-6 (2000): I037-I055.

59. De Gregorio, "Políticas urbanas", I3. Según datos de la Comisión Europea, durante el periodo de programación 1994-1999, Urban I financió programas en un total de II8 zonas urbanas. La aportación comunitaria se aproximó a 900 millones de euros, lo que permitió una inversión total subvencionable de 1800 millones de euros que redundaron en beneficio de 3.2 millones de personas en toda Europa. Por su parte, durante el programa Urban II (2000-2006) participaron 70 ciudades de I4 países distintos. La aportación comunitaria superó los 700 millones de euros, y permitió una inversión total subvencionable de más de 1500 millones de euros, consultado el 30 de enero de 20I7, en http://ec.europa.eu/regional_policy/archive/urban2/towns_prog_es.htm. 
abandonar progresivamente la temática residencial que caracterizó las siete primeras ediciones del concurso desde su inicio en 1990. A este respecto, el Europan 8 (2004-2006) marcó el inicio de una nueva era del urbanismo europeo caracterizada por el diseño de estrategias enfocadas a la revalorización del espacio público, el acondicionamiento de las infraestructuras urbanas para la atracción de capitales y el fomento de la iniciativa privada para la regeneración de la ciudad.

Desde este punto de vista, las últimas ediciones del mismo se focalizaron en el diseño de políticas culturales participativas para la activación de "recursos comunes" (Europan II), la revitalización de barrios residenciales mediante la mezcla de usos y la formación de redes territoriales (Europan I2) o el establecimiento de nuevos modos de cooperación entre agentes públicos y desarrolladores privados, la redefinición del arquitecto como emprendedor urbano, o el fomento del crowdfunding para el desarrollo de intervenciones temporales (Europan 13 ).

Por su parte, la guía temática de su última edición (Europan I4), que finalizó en diciembre de 20I7, predeterminó las seis estrategias fundamentales de regeneración urbana que deben seguir obligatoriamente los proyectos propuestos por los municipios: ${ }^{60}$ I) reactivación de áreas residenciales monofuncionales en barrios productivos mixtos que exploten la producción de valor de ciudadanos no residentes; 2) implantación de viviendas y equipamientos en áreas de negocios que extiendan su producción de valor más allá del horario laboral; 3) transformación de las calles vertebradoras de la ciudad en calles productivas; 4) diseño de edificios multifuncionales en barrios consolidados; 5) desarrollo de territorios suburbanos híbridos en las periferias mediante técnicas de agricultura urbana con circuitos de distribución cortos, y 6) regeneración de terrenos industriales obsoletos mediante prácticas urbanas innovadoras de ocupación temporal.

Respecto a las EDUSI, la Comisión Europea entiende por DUSI todo conjunto de "medidas que atañen a la renovación física de las ciudades [y que] deben combinarse con medidas que promuevan la educación, el desarrollo económico, la inclusión social y la protección del medio ambiente", ${ }^{61}$ y se establece como requisito indispensable para poder acceder a la calificación de integra-

6o. En esta edición han presentado concurso un total de 40 municipios europeos pertenecientes a I3 estados miembros distintos.

6I. Comisión Europea, DUSI: Desarrollo urbano sostenible integrado. Politicas de cohesión 20I42020 (Bruselas: Comisión Europea, 2014), 2. 
do "el desarrollo de una sólida cooperación entre los ciudadanos locales, la sociedad civil, la economía local y los diversos estamentos gubernamentales". ${ }^{62}$

O lo que es lo mismo, se busca un acondicionamiento integral del medio que permita hacer productiva la libre actuación de los individuos mediante una cuádruple colaboración o "participación” entre I) administraciones públicas territoriales según el eje UE-estados miembros-regiones-municipios (integración administrativa vertical); 2) órganos administrativos sectoriales como vivienda, urbanismo, servicios sociales, medio ambiente, educación, cultura y turismo (Integración Administrativa Horizontal); 3) agentes público-privados implicados como asociaciones, fundaciones, ONGs, sociedades mercantiles públicas y privadas, entidades financieras y centros de investigación (consolidación de gobernanzas), y por último 4) la población destinataria de las políticas públicas (participación ciudadana).

Si bien las principales críticas al urbanismo biopolítico de las smart cities se ha venido haciendo desde posturas cercanas a una filosofía de los comunes urbanos indiscriminadamente fusionada con el tipo de urbanismo participativo realizado a partir de los programas Urban, resulta sintomático comprobar cómo los principales cuestionamientos de este último ${ }^{63}$ suelen fundamentar sus argumentaciones en una concepción foucaultiana del poder que muestra el modo en que las estrategias de participación integral y la búsqueda del consenso funcionan realmente como un dispositivo gubernamental orientado a encubrir un conflicto subyacente imposible de ser superado por el simple diálogo entre los participantes. ${ }^{64}$

De este modo, en lugar de proponer el urbanismo participativo como solución o contrapeso a las smart cities, un análisis foucaultiano de la arquitectura

62. Comisión Europea, DUSI, 2.

63. Marit Rosol, "Governing Cities Through Participation. A Foucauldian Analysis of City Plan Vancouver”, Urban Geography 36, núm. 2 (2015), 256-276; Mark Purcell, "Resisting NeoLiberalization: Communicative Planning or Counter-Hegemonic Movements?”, Planning Theory 8, núm. 2 (2009): I40-165; Jean Hillier, "Agonizing over Consensus: Why Habermasian Ideals cannot be 'Real'", Planning Theory 2, núm. I (2003): 37-59; Bent Flyvbjerg, "Habermas and Foucault: Thinkers for Civil Society?”, The British Journal of Sociology 49, núm. 2 (I998): 210-233.

64. Ahora bien, la postura académica mayoritaria continúa insistiendo en el consenso y la colaboración como técnicas que siempre juegan a favor del empoderamiento ciudadano (Judith E. Innes y David E. Booher, Planning with Complexity: an Introduction to Collaborative Rationality for Public Policy [Abingdon: Routledge, 20Io]; John Forester, The Deliberative Practitioner: Encouraging Participatory Planning Processes [Cambridge: MIT Press, 1999]; Patsy Healey, Collaborative Planning: Shaping Places in Fragmented Societies [Londres: Macmillan, 2006]). 
y el urbanismo permite comprobar cómo la línea dura del urbanismo biopolítico definida por las smart cities se complementa con una línea blanda definida mediante el eje Urban-Europan-EDusi que ha aprendido bien la lección dada por el fracaso del urbanismo disciplinar según la cual "el índice represivo no elimina, sino que exalta la eficacia de los procesos de autovalorización, es decir, de la reproducción del antagonismo de clase en la reproducción del capital". ${ }^{65}$ Debido a ello, el urbanismo biopolítico ha generado, además de la adecuación territorial de las smart cities, una adecuación sociojurídica orientada a eludir la aparición del antagonismo de clase mediante la integración participativa de la población en una acomodación integral del medio.

A este respecto, la gran aportación del urbanismo biopolítico neoliberal frente al liberalismo clásico reside en que mientras que el régimen fisiócrata ya introducía la libertad de los individuos en el mercado como parte de la ecuación gubernamental, en modo alguno tuvo la intención de ceder a los gobernados la gestión para el acondicionamiento del medio territorial, ni mucho menos del jurídico. El control del espacio urbano y del régimen jurídico seguía siendo competencia exclusiva del poder político. Lejos de ser un instrumento para la liberación o empoderamiento de los gobernados, el urbanismo participativo es el modo hegemónico de volver productivos tanto a la población como al territorio.

Frente al urbanismo biopolítico participativo desarrollado en Europa, la teoría de los comunes propone el urbanismo autogestionado por la comunidad aymara en Bolivia como uno de los casos paradigmáticos de resistencia frente al biopoder. Fruto de las emigraciones masivas del campo a la ciudad durante la década de los ochenta, los nuevos asentamientos de El Alto se desarrollaron de forma autónoma y sin control alguno por parte de la administración, se autogestionaban en torno a juntas vecinales cuyos únicos requisitos para obtener el reconocimiento por parte de la Federación de Juntas era estar en posesión de un plano de urbanización y haber reunido 200 familias (Iooo vecinos).

La organización interna de cada junta vecinal desarrollaba planos de loteamiento, ubicación de cada predio, número y propietario de cada lote, registro de títulos de propiedad y pagos de impuestos. Si bien la propiedad de los lotes es individual (privada), la necesidad de mantener dicha propiedad por razones de (in)seguridad, así como la posibilidad de poner en marcha servicios públicos básicos que la Administración no proporcionaba, promovió un gran desa- 
rrollo de la gestión común(al) frente a lo público: el límite de 200 familias por junta vecinal se determinó en función de la posibilidad de realizar asambleas generales con democracia directa y se promovió una rotación (no-división) del trabajo que contribuyó tanto a una no-zonificación del espacio urbano como a una autogestión del tiempo de trabajo. La posibilidad de la continuidad de dicho sistema radicó en el rechazo sistemático de los aymaras a toda colaboración o integración participativa con la administración pública que implicara el abandono de su modalidad de autogestión.

De manera sintomática, el informe encargado por la agencia estadounidense para el desarrollo internacional de Bolivia afirmaba la necesidad de superar las organizaciones vecinales, "actualmente fragmentadas y atomizadas, para poder implementar procesos de profundización democrática y responsabilidad ciudadana" ${ }^{66}$ En concreto, frente a las juntas vecinales de no más de IOoo habitantes en torno a las cuales se organiza la autogestión urbanística en El Alto, el citado informe proponía la necesidad de articular esas juntas vecinales en barrios de entre 5000 y 8000 habitantes como "umbrales mínimos de vida en comunidades urbanas". ${ }^{67} \mathrm{El}$ objetivo último era, por tanto, crear población.

\section{Conclusiones}

En este trabajo hemos intentado mostrar las diversas relaciones existentes entre espacio (óptico-geométrico o virtual) y técnicas de poder (arquitectura, urbanismo, ordenación del territorio) según el paradigma gubernamental desde el que se ejercen (disciplinario o biopolítico). Igualmente hemos visto cómo en la transformación del poder disciplinario en biopolítico, y de éste en neoliberalismo, se ha producido una progresiva virtualización del espacio que ha sustituido el carácter panóptico-geométrico del soporte disciplinar en el que se producían las relaciones de poder-visibilidad por una gestión informatizada de datos que, propiamente hablando, construye más que identifica tanto su objeto de gobierno como su medio de actuación.

66. Raúl Zibechi, Dispersar el poder. Los movimientos sociales como poderes antiestatales (Barcelona: Virus, 2007), 65.

67. Zibechi, Dispersar el poder, 66. 
Mientras que el objetivo último del urbanista disciplinar era arquitecturar el espacio para normalizar a los individuos y controlar la producción mediante dispositivos de vigilancia, el nuevo urbanista biopolítico, más allá de limitarse a acondicionar el medio territorial de modo que se optimicen las relaciones de producción, ha dado un paso más mediante la introducción de un urbanismo participativo orientado al establecimiento de redes público-privadas que fomenten la autoorganización productiva de la sociedad por medio de su libre actuación no sólo en el mercado, sino también en la configuración de las políticas públicas. Así, en continuidad con el planteamiento realizado por Foucault, el urbanista biopolítico se ha transformado en un gestor integral del medio que fomentan la autoorganización de la población como capital social. ${ }^{68}$

Si bien la concepción foucaultiana de la arquitectura y el urbanismo como técnicas de poder insertas en un complejo entramado de relaciones de fuerzas ya había anunciado la imposibilidad de que pudieran llegar a funcionar como saberes capaces de generar por sí solos la liberación y el empoderamiento de los ciudadanos, ${ }^{69}$ el análisis de los últimos desarrollos del urbanismo biopolítico que Foucault no pudo realizar ha mostrado cómo la última esperanza del autor francés respecto a la disciplina arquitectónica como técnica de liberación parece haber entrado definitivamente en crisis.

Por ello, mientras que Foucault todavía consideraba que "la arquitectura puede producir, y produce, efectos positivos [únicamente] cuando las intenciones liberadoras de la arquitectura coinciden con la práctica real de la gente en el ejercicio de su libertad", ${ }^{70}$ el análisis realizado sobre los últimos desarrollos europeos del urbanismo participativo ha evidenciado la aparición de un nuevo dispositivo o aparato de captura orientado de hecho a redirigir el ejercicio de la libertad de las personas hacia consideraciones tan sólo productivas, de modo que no siempre serán los ciudadanos aquellos que reciban los beneficios derivados de la revalorización del espacio urbano que promuevan sus actuaciones.

Hoy más que nunca, resulta necesario volver a desarrollar el potencial del pensamiento foucaultiano por el cual, al menos dentro del paradigma de poder biopolítico, la libertad no es otra cosa que "el correlato de la introducción de

68. La biopolítica se ocupa del hábitat, de las condiciones de vida en la ciudad y de la higiene pública (Foucault, Las redes de poder, 59).

69. Discurso aún mantenido por la apología de las heterotopías realizada desde la disciplina arquitectónica.

70. Foucault, El cuerpo utópico, 94. 
los dispositivos de seguridad"..$^{7}$ Si bien Foucault dejó claro que no existen máquinas de libertad, tanto el tipo de urbanismo biopolítico desarrollado por las smart cities como el planteado por el modelo participativo europeo muestran que tampoco es seguro que existan prácticas de libertad al margen de una constitución realmente antagónica de los ciudadanos frente a la administración pública y el sistema de libre mercado. Una vez ahí, el principal problema de un urbanismo en verdad antagónico radica de nuevo en cómo lograr ir más allá de una simple federación de microjuntas para ser capaces de dar respuesta al exponencial incremento de movilidad de la población con el ámbito global. \$

7I. Foucault, Seguridad, territorio y población, 7I.

N.B. Este artículo recoge resultados de la investigación "Mapa de Riesgo Social” financiada por el Ministerio de Economía y Competitividad, Programa de I+D+i orientada a los Retos de la Sociedad, 2013. Referencia: CSO2O13-42576-R. 